\title{
99.3\% Efficient Three-Phase Buck-Type All-SiC SWISS Rectifier for DC Distribution Systems
}

\author{
L. Schrittwieser*, M. Leibl*, M. Haider*, F. Thöny*, J. W. Kolar* and T. B. Soeiro ${ }^{\dagger}$ \\ Power Electronic Systems Laboratory, ETH Zurich, Switzerland, Email: schrittwieser@lem.ee.ethz.ch \\ ${ }^{\dagger}$ ABB Switzerland Ltd., Corporate Research, 5405 Baden-Dättwil, Switzerland
}

\begin{abstract}
DC power distribution systems for data centers, industrial applications and residential areas are expected to provide higher efficiency, reliability and lower cost compared to ac systems. Accordingly they have been an important research topic in recent years. In these applications an efficient power factor correction rectifier, supplying a de distribution bus from the conventional three-phase ac mains is typically required. This paper analyzes the three-phase buck-type unity power factor SWISS Rectifier showing that its input current THD can be improved significantly by interleaving. The dc output filter is implemented using a current compensated Integrated Common Mode Coupled Inductor which ensures equal current sharing between interleaved half bridges and provides common mode inductance. Based on the analysis an high efficient $8 \mathrm{~kW}, 4 \mathrm{~kW} \mathrm{dm}^{-3}\left(64 \mathrm{~W}^{-3}\right)$ lab-scale prototype converter is designed using $\mathrm{SiC}$ MOSFETS. Measurements taken on a hardware prototype confirm a full power efficiency of $99.16 \%$ and a peak efficiency of $99.26 \%$.
\end{abstract}

\section{INTRODUCTION}

Over the last decades the power demand of intrinsic dc loads, such as information and communication technology equipment, data centers, electric vehicle battery charging, LED lighting, etc. increased substantially. Furthermore renewable energy sources such as PV modules, fuel cells and battery storage are also based on dc. Therefore, dc distribution systems are expected to give advantages in terms of efficiency, reliability and/or cost as the total number of conversion stages can be reduced. Consequently, dc power supply and distribution systems for information and communication technology equipment, electric vehicle traction battery fast charging and dc microgrids have been a major topic in research and industry in recent years and corresponding standards have been created [1-9].

In these applications loads, with typically tens of kilowatts or more, are supplied from a dc bus with $\approx 400 \mathrm{~V}$ which is powered from the conventional $400 \mathrm{~V}$ or $480 \mathrm{~V}$ rms threephase ac mains. Due to the high power levels sinusoidal ac input currents, in-phase with the mains voltage are required. As the dc bus voltage is lower than the amplitude of the full-wave rectified three-phase line-to-line voltage, two-stage systems are normally used which consist of a boost-type power factor correction (PFC) rectifier front end providing $\approx 800 \mathrm{~V} \mathrm{dc}$ and a subsequent step-down dc-dc converter. Buck-type PFC rectifiers, which allow a direct conversion from the three-phase ac mains to a dc bus with lower voltage, are an advantageous alternative offering potentially lower losses, volume and cost [11].

The schematic of the three-phase buck-type SWISS Rectifier introduced in [10] is shown in Fig. 1(a). It consists of an ac-side EMI input filter, an Input Voltage Selector (IVS) and
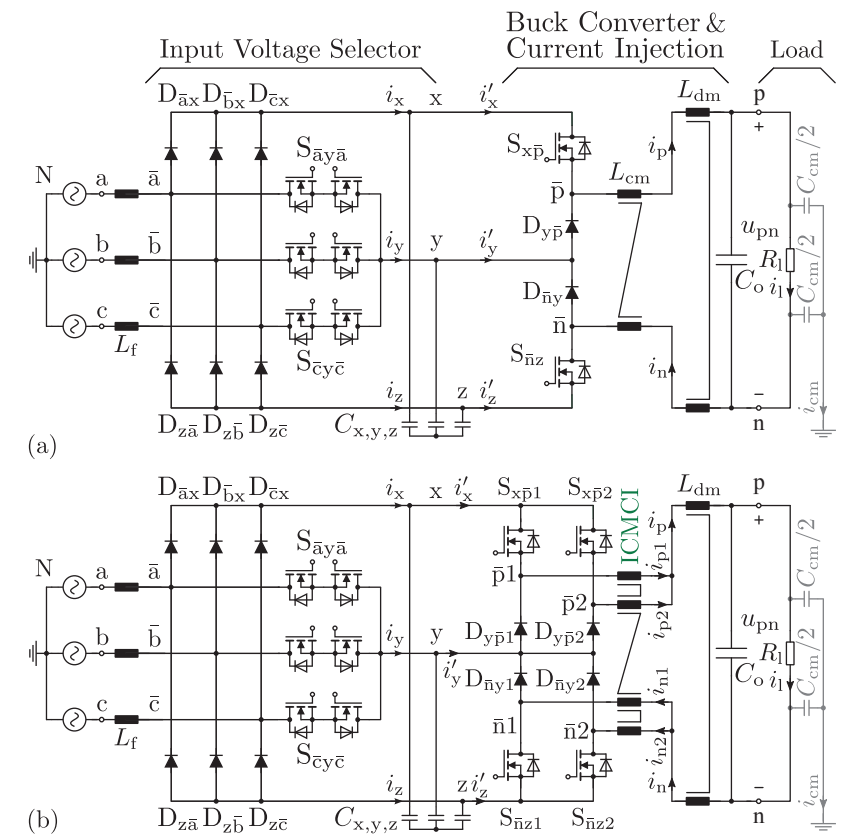

Fig. 1. (a) Three-phase buck-type SWISS Rectifier consisting of an EMI input filter, an Input Voltage Selector commutated at mains frequency and two dc-dc buck converters as proposed in [10]. (b) Interleaved SWISS Rectifier using a novel four winding current compensated Integrated Common Mode Coupled Inductor (ICMCI) which is used to ensure equal current sharing $i_{\mathrm{p} 1} \approx i_{\mathrm{p} 2}, i_{\mathrm{n} 1} \approx i_{\mathrm{n} 2}$ and provides common mode inductance.

TABLE I

CONVERTER SPECIFICATIONS

\begin{tabular}{ll}
\hline Input Voltage (Line-to-Neutral) & $U_{1}=230 \mathrm{~V} \mathrm{rms}$ \\
Input Frequency & $\omega_{1}=2 \pi 50 \mathrm{~Hz}$ \\
Switching Frequency & $f_{\mathrm{s}}=27 \mathrm{kHz}$ \\
Nominal Output Voltage & $U_{\mathrm{pn}}=400 \mathrm{~V}$ \\
Nominal Output Power & $P=8 \mathrm{~kW}$ \\
DM Output Inductance & $L_{\mathrm{dm}}=350 \mu \mathrm{H}$ \\
CM Output Inductance & $L_{\mathrm{cm}}=600 \mu \mathrm{H}$ \\
\hline
\end{tabular}

two series-connected buck-type dc-dc converters $S_{x \bar{p}}, D_{y \bar{p}}$ and $\mathrm{S}_{\overline{\mathrm{n}} \mathrm{z}}, \mathrm{D}_{\overline{\mathrm{n}} \mathrm{y}}$. Note that all diodes and switches in the IVS are commutated at mains frequency only, therefore basically no switching losses occur in the IVS. Hence, diodes with a low forward voltage drop, or MOSFET-based synchronous rectifiers can be used in the IVS. The IVS output voltages $u_{\mathrm{x}}, u_{\mathrm{y}}, u_{\mathrm{z}}$ are piece-wise sinusoidal as the input phase with highest potential is connected to node $\mathrm{x}$, the one with lowest potential to $\mathrm{z}$ and the remaining phase to node $\mathrm{y}$.

In this paper the conventional (single buck converter output stage), cf. Fig. 1(a), and interleaved SWISS Rectifier, cf. Fig. 1(b), are compared regarding their ac input and dc 
(a) Non-Interleaved
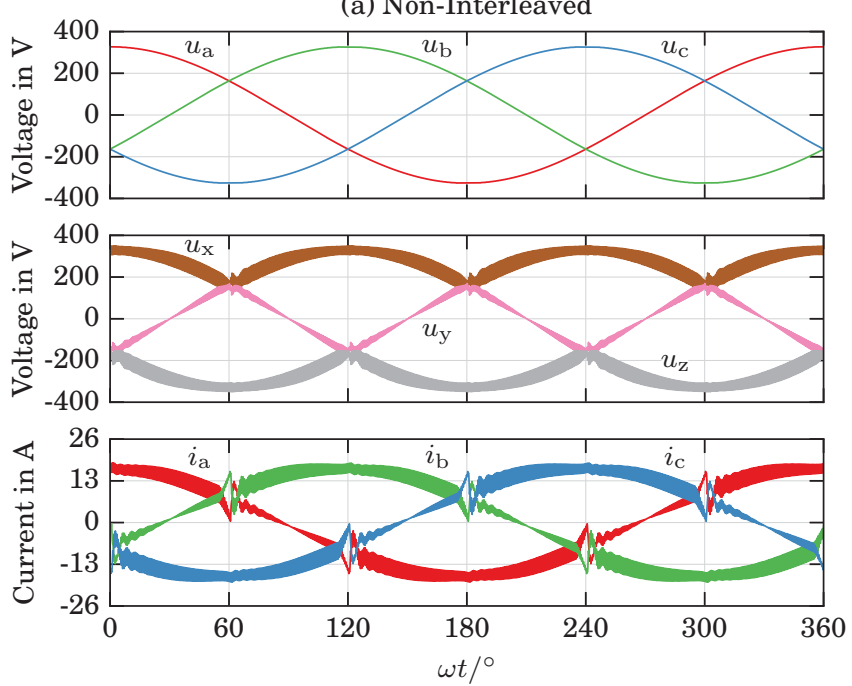

(b) Interleaved
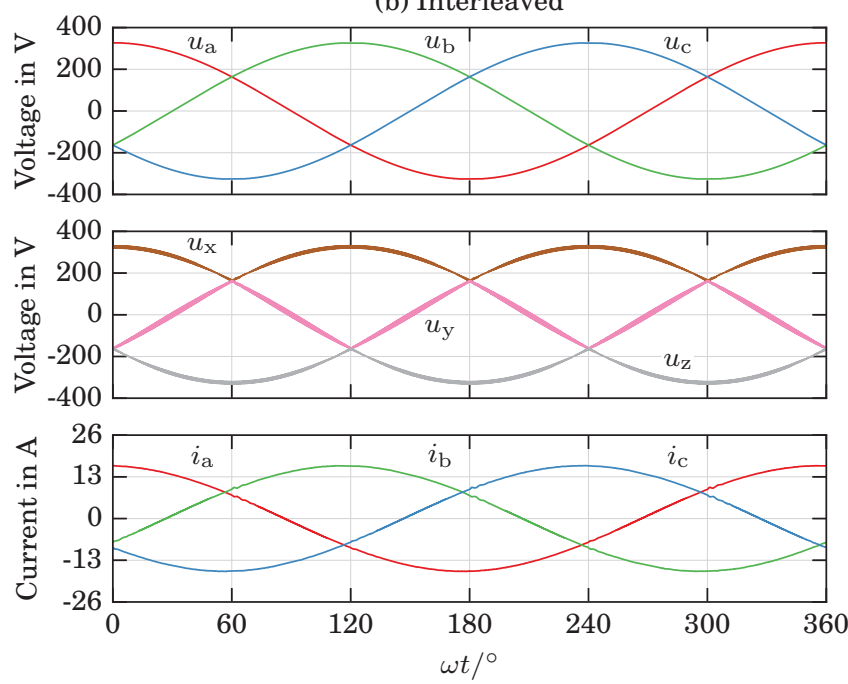

Fig. 2. Simulation results for an $8 \mathrm{~kW}$ SWISS Rectifier as specified in Table $\mathbf{I}$, showing the ac input voltages $u_{\mathrm{a}, \mathrm{b}, \mathrm{c}}$, the filter capacitor voltages $u_{\mathrm{x}, \mathrm{y}, \mathrm{z}}$ and the resulting ac input currents $i_{\mathrm{a}, \mathrm{b}, \mathrm{c}}$. (a) Due to the discontinuous input currents $i_{\mathrm{x}, \mathrm{y}, \mathrm{z}}^{\prime}$ of the non-interleaved dc-dc buck converters a high ripple in $u_{\mathrm{x}, \mathrm{y}, \mathrm{z}}$ and in the ac input currents $i_{\mathrm{a}, \mathrm{b}, \mathrm{c}}$ results. This also leads to significant distortions in $i_{\mathrm{a}, \mathrm{b}, \mathrm{c}}$ as described in [12]. (b) In the interleaved SWISS Rectifier the switching frequency voltage ripples of $u_{\mathrm{x}, \mathrm{y}, \mathrm{z}}$ are reduced significantly due to harmonic cancellation. Therefore the ac input current $\left(i_{\mathrm{a}, \mathrm{b}, \mathrm{c}}\right)$ ripple and the resulting distortion at sector boundaries are reduced as well.

output properties in Section II. The implemented prototype converter is presented in Section III, including measurement results.

\section{SWISS RECTIFIER}

\section{A. Non-Interleaved SWISS Rectifier}

In Fig. 1(a) the SWISS Rectifier with two coupled dc output inductors $L_{\mathrm{cm}}$ (common mode) and $L_{\mathrm{dm}}$ (differential mode) is shown. As the dc load is connected between output nodes $\mathrm{p}$ and $\mathrm{n}$ of the converter and has no connection to the star point $\mathrm{N}$ of the ac mains $i_{\mathrm{p}}=i_{\mathrm{n}}$ can usually be assumed and the differential mode inductor alone would be sufficient. However, this is not the case if the load is, for example, a widespread dc distribution bus, potentially including physically large backup batteries, which can have a significant capacitance $C_{\mathrm{cm}}$ to ground. This creates a conduction path for high frequency common mode $(\mathrm{cm})$ currents $i_{\mathrm{cm}}$ from the output nodes $\mathrm{p}$ and $\mathrm{n}$ to the grounded star point $\mathrm{N}$ as shown in Fig. 1, which is also the case if dedicated $\mathrm{cm}$ capacitors are added to the converter as part of a $\mathrm{cm}$ filter, which is typically required to comply with EMI regulations.

Simulation results for a conventional non-interleaved $8 \mathrm{~kW}$ SWISS Rectifier specified in Table I are shown in Fig. 2(a). It can be seen that the ac input currents $i_{\mathrm{a}}, i_{\mathrm{b}}, i_{\mathrm{c}}$ show a significant switching frequency ripple and distortions with an amplitude of $\approx 6 \mathrm{~A}$ at every $60^{\circ}$ mains voltage sector boundary. Detailed simulation results for the vicinity of the first sector boundary at $\omega t \approx 60^{\circ}$ are shown in Fig. 3(a). These distortions are due to the switching frequency voltage ripple on the filter capacitors $C_{\mathrm{x}, \mathrm{y}, \mathrm{z}}$ as described in [12]. As $u_{\mathrm{x}}, u_{\mathrm{y}}$ and $u_{\mathrm{z}}$ are piece-wise sinusoidal due to the IVS operation, $C_{\mathrm{x}, \mathrm{y}, \mathrm{z}}$ create reactive power at the ac input which typically has to be limited to a few percent of the converter's rated output power, which limits the capacitance value of
$C_{\mathrm{x}, \mathrm{y}, \mathrm{z}}$. As the SWISS Rectifier is a buck-type topology the input currents $i_{\mathrm{x}}^{\prime}, i_{\mathrm{y}}^{\prime}$ and $i_{\mathrm{z}}^{\prime}$ of the dc-dc converter are discontinuous which, in connection with the limited capacitance of $C_{\mathrm{x}, \mathrm{y}, \mathrm{z}}$ results in a high switching frequency ripple of $u_{\mathrm{x}}, u_{\mathrm{y}}$ and $u_{\mathrm{z}}$, cf. Fig. 3(a).

\section{B. SWISS Rectifier with Interleaved Output Stages}

To reduce the input current and voltage ripples either the ac input filter capacitance and inductance can be increased or a higher switching frequency can be used. Both options increase volume, losses and cost of the converter system. In order to overcome these disadvantages two interleaved dc-dc converters can be used as output stage to reduce the input and output current ripples [13]. The schematic of the resulting system, denominated as interleaved SWISS Rectifier in the following, is shown in Fig. 1(b) where two individual bridge legs $S_{x \bar{p} 1} / D_{y \bar{p} 1}$ and $S_{x \bar{p} 2} / D_{y \bar{p} 2}$ are used for the $\mathrm{p}$ side dc-dc converter stage and $S_{\bar{n} z 1} / D_{\bar{n} y 1}, S_{\bar{n} z 2} / D_{\bar{n} y 2}$ are used for the $\mathrm{n}$ side. By using the same duty cycle but $180^{\circ}$ phase shifted carriers for the pulse width modulation of $S_{x \bar{p} 1}$ and $S_{x \bar{p} 2}$ the high frequency components of the resulting input current $i_{\mathrm{x}}^{\prime}$ have twice the frequency and half the amplitude compared to the non-interleaved case as shown in the detailed simulation results in Fig. 3(b).

Simulation results of the interleaved SWISS Rectifier are shown in Fig. 2(b), where it can be seen that the differential mode $(\mathrm{dm})$ and $\mathrm{cm}$ current ripples are reduced significantly compared to Fig. 2(a). Detailed simulation results for the first mains voltage intersection are shown in Fig. 3(b). Due to the reduced ripple of the buck converter input currents $i_{\mathrm{x}}^{\prime}, i_{\mathrm{y}}^{\prime}$ and $i_{\mathrm{z}}^{\prime}$, the peak-peak ripple on the filter capacitor voltages $u_{\mathrm{x}}$, $u_{\mathrm{y}}$ and $u_{\mathrm{z}}$ reduces from $105 \mathrm{~V}$ without interleaving to $24 \mathrm{~V}$ with interleaving. Also the ripple and the distortions of the input currents $i_{\mathrm{a}}, i_{\mathrm{b}}$ and $i_{\mathrm{c}}$ occurring at every $60^{\circ}$ mains voltage sector boundary are reduced from $\approx 6 \mathrm{~A}$ to $<1 \mathrm{~A}$. 
(a) Non-Interleaved
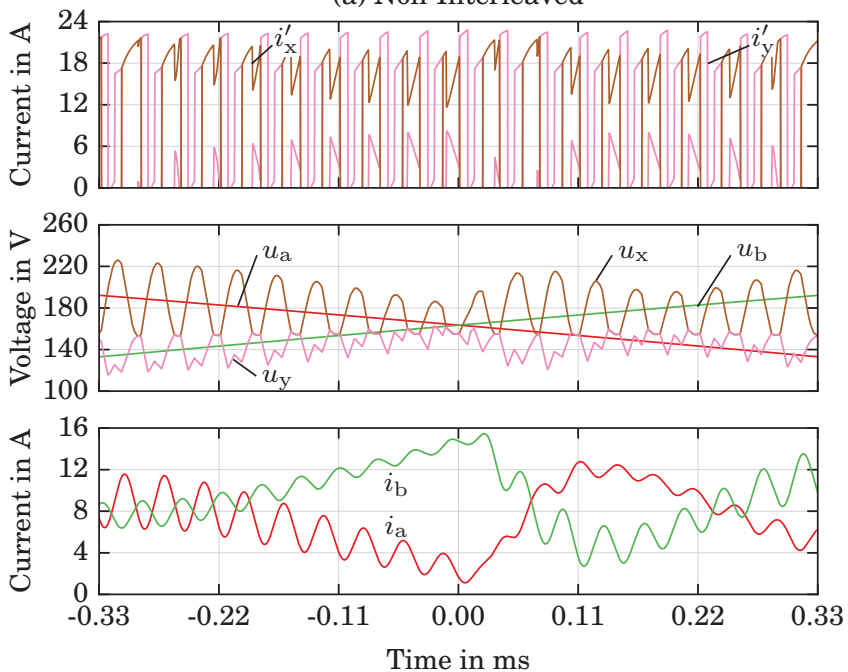

(b) Interleaved
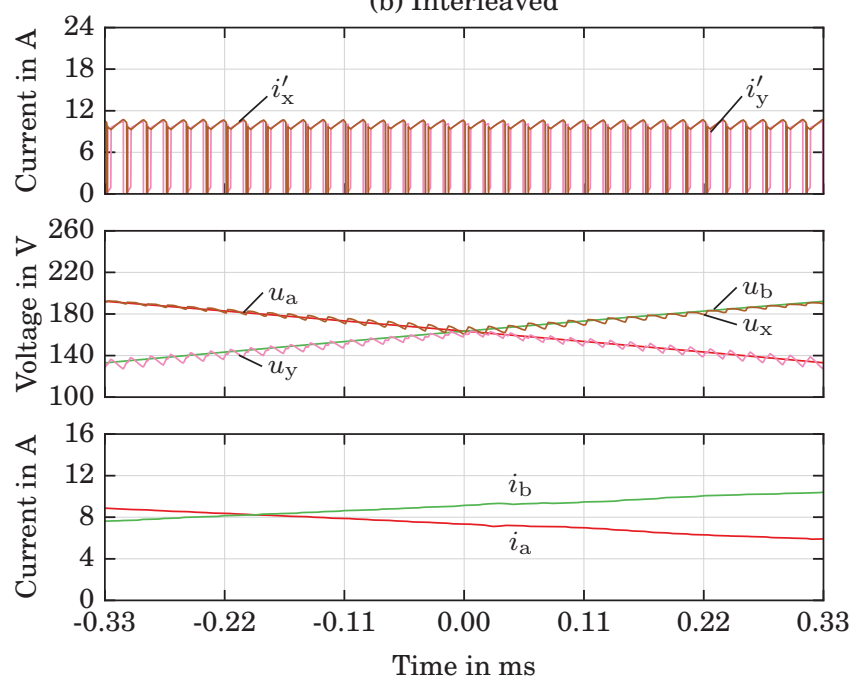

Fig. 3. Detailed simulation results of the first intersection of the mains line-to-neutral voltages $u_{\mathrm{a}}$ and $u_{\mathrm{b}}$ at $\omega t \approx 60^{\circ}:(\mathbf{a})$ the discontinuous buck converter input currents $i_{\mathrm{x}}^{\prime}, i_{\mathrm{y}}^{\prime}$ of the non-interleaved SWISS Rectifier lead to high switching frequency ripples of the input filter capacitor voltages $u_{\mathrm{x}}$ and $u_{\mathrm{y}}$. As $u_{\mathrm{x}}$ and $u_{\mathrm{y}}$ cannot intersect due to $\mathrm{D}_{\mathrm{y} \overline{\mathrm{p}}}$ and $\mathrm{S}_{\mathrm{x} \overline{\mathrm{p}}}$ a distortion of the mains currents $i_{\mathrm{a}}$ and $i_{\mathrm{b}}$ results [12]. (b) In case of an interleaved SWISS Rectifier the amplitude of $i_{\mathrm{x}}^{\prime}, i_{\mathrm{y}}^{\prime}$ is reduced and the frequency is doubled which leads to a significant reduction of the ripples in $u_{\mathrm{x}}$ and $u_{\mathrm{y}}$.

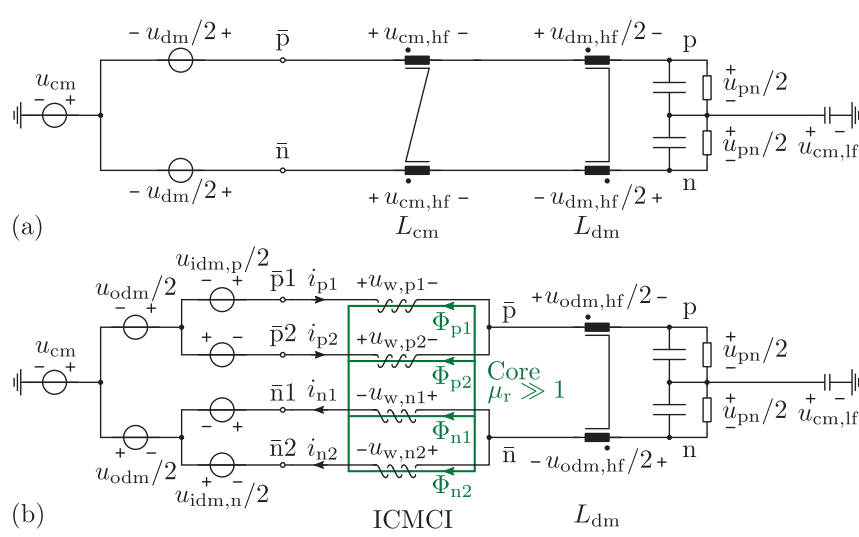

Fig. 4. Simplified circuit diagram of (a) the conventional and (b) the interleaved SWISS Rectifier where the IVS and the dc-dc converters are replaced by equivalent voltage sources split into common mode, outer- and inner differential mode.

Note that the interleaved buck converters can be controlled such that the individual dc-dc converter currents are split equally, i.e. $i_{\mathrm{p} 1}=i_{\mathrm{p} 2}$ and $i_{\mathrm{n} 1}=i_{\mathrm{n} 2}$ except for a switching frequency ripple. This implies that current compensated filtering of the dc-dc converter output voltages can be accomplished with close-coupled inductors. Ideally they carry no dc flux component and can be implemented without an air-gap, leading to a larger inductance value, similar to a $\mathrm{cm}$ inductor. Typically this is implemented with so called Intercell Transformers (ICTs) [14-16], were the interleaved SWISS Rectifier would require two ICTs, one for the $\mathrm{p}$ and one for the $\mathrm{n}$ side bridges. However, the two ICTs and the $\mathrm{cm}$ inductor $L_{\mathrm{cm}}$ can be integrated into a single four winding magnetic device in the following denominated as Integrated Common Mode Coupled Inductor (ICMCI) as shown in Fig. 1(b) and Fig. 4(b).

\section{Integrated Common Mode Coupled Inductor - ICMCI}

In order to analyze the properties of the ICMCI the SWISS Rectifier's input filter, IVS and dc-dc converters are replaced by equivalent voltage sources which define the potentials of nodes $\bar{p} 1, \bar{p} 2, \bar{n} 1$ and $\bar{n} 2$ with respect to the mains star point and/or ground. Furthermore, these four voltage sources can be converted to a tree structure of a common mode $(\mathrm{cm})$, an outer differential mode (odm) and two inner differential modes (idm) as shown in Fig. 4(b). A similar equivalent circuit of the conventional SWISS Rectifier is shown in Fig. 4(a) for comparison. These equivalent voltages can be derived as

$$
\begin{aligned}
u_{\mathrm{cm}} & =\frac{u_{\overline{\mathrm{p}} 1}+u_{\overline{\mathrm{p}} 2}+u_{\overline{\mathrm{n}} 1}+u_{\overline{\mathrm{n}} 2}}{4}, \\
u_{\mathrm{odm}} & =\frac{u_{\overline{\mathrm{p}} 1}+u_{\overline{\mathrm{p}} 2}}{2}-\frac{u_{\overline{\mathrm{n}} 1}+u_{\overline{\mathrm{n}} 2}}{2}, \\
u_{\mathrm{idm}, \mathrm{p}} & =u_{\overline{\mathrm{p}} 1}-u_{\overline{\mathrm{p}} 2} \\
u_{\mathrm{idm}, \mathrm{n}} & =u_{\overline{\mathrm{n}} 1}-u_{\overline{\mathrm{n}} 2} .
\end{aligned}
$$

Neglecting any stray fields in the ICMCI the fluxes $\Phi_{\mathrm{p} 1}$, $\Phi_{\mathrm{p} 2}, \Phi_{\mathrm{n} 1}, \Phi_{\mathrm{n} 2}$ generated by the four windings have to sum up to zero due to the ICMCI's core, cf. Fig. 4(b):

$$
\Phi_{\mathrm{p} 1}+\Phi_{\mathrm{p} 2}+\Phi_{\mathrm{n} 1}+\Phi_{\mathrm{n} 2}=0 .
$$

This implies that the voltages applied to the four windings sum to zero as well due to inverse winding direction of the $p$ and $\mathrm{n}$ side ICMCI windings. Using Kirchhoff's voltage law on the circuit shown in Fig. 4(b) three additional equations can be found, which yields four equations that define the ICMCI's voltages

$$
\begin{aligned}
u_{\mathrm{w}, \mathrm{p} 1}+u_{\mathrm{w}, \mathrm{p} 2}+u_{\mathrm{w}, \mathrm{n} 1}+u_{\mathrm{w}, \mathrm{n} 2} & =0, \\
u_{\mathrm{w}, \mathrm{p} 1}-u_{\mathrm{w}, \mathrm{p} 2} & =u_{\mathrm{idm}, \mathrm{p}}, \\
-u_{\mathrm{w}, \mathrm{n} 1}+u_{\mathrm{w}, \mathrm{n} 2} & =u_{\mathrm{idm}, \mathrm{n}}, \\
u_{\mathrm{w}, \mathrm{p} 1}+u_{\mathrm{w}, \mathrm{p} 2}-u_{\mathrm{w}, \mathrm{n} 1}-u_{\mathrm{w}, \mathrm{n} 2} & =4 u_{\mathrm{cm}, \mathrm{hf}} .
\end{aligned}
$$


(a) Non-Interleaved
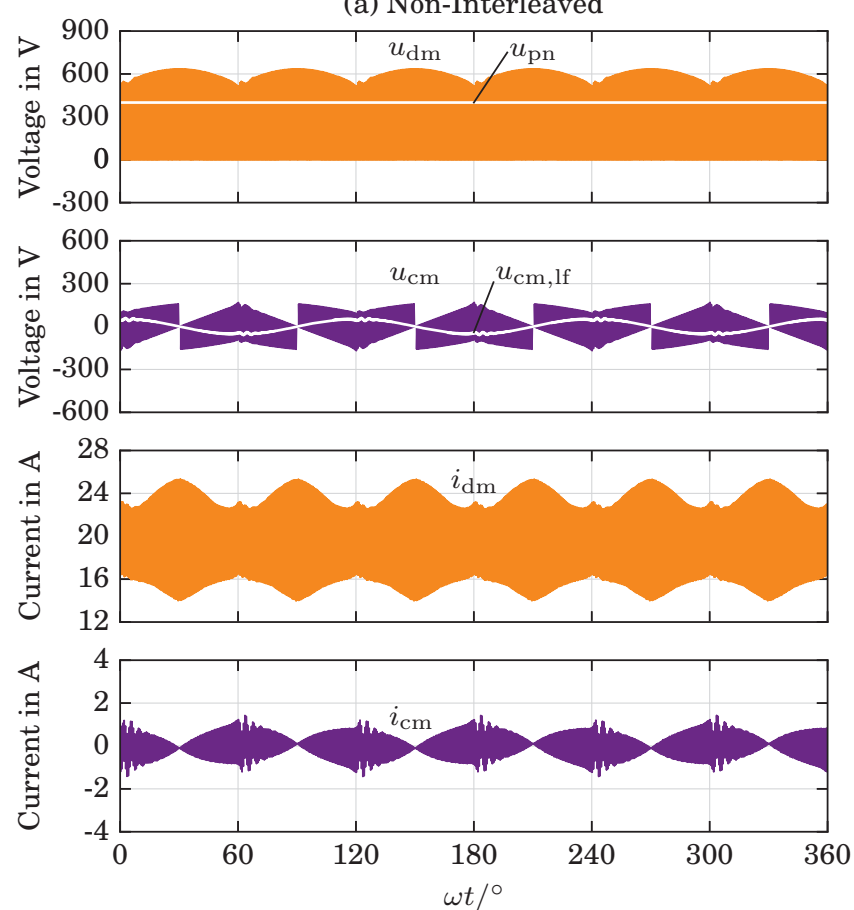

(b) Interleaved
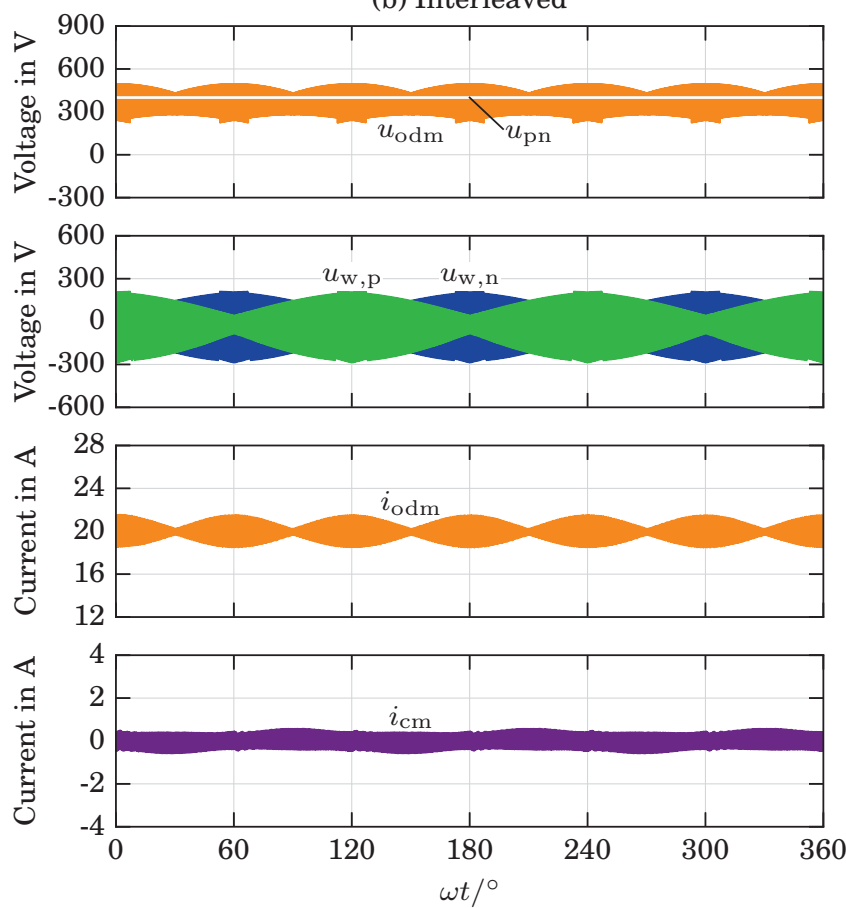

Fig. 5. (a) Detailed simulation results for a non-interleaved SWISS Rectifier with the same operating conditions as in Fig. 2, showing dm and cm voltages $u_{\mathrm{dm}}$ and $u_{\mathrm{cm}}$ created by the dc-dc converters and the resulting $\mathrm{dm}$ and cm currents $i_{\mathrm{dm}}$ and $i_{\mathrm{cm}}$. (b) Simulation results of the corresponding quantities of an interleaved SWISS Rectifier using an ICMCI. Due to the interleaving the outer differential mode (odm) voltage $u_{\text {odm }}$ peak-to-peak value reduces, which leads to a reduction of the ripple in the corresponding current $i_{\text {odm }}$.

Note that $u_{\mathrm{cm}, \mathrm{hf}}$ is the switching frequency component of the converter's cm voltage $u_{\mathrm{cm}}$ as given by (1). Solving the system of equations given by (6) to (9) with respect to the ICMCI's winding voltages yields

$$
\begin{aligned}
& u_{\mathrm{w}, \mathrm{p} 1}=u_{\mathrm{idm}, \mathrm{p}} / 2+u_{\mathrm{cm}, \mathrm{hf}}, \\
& u_{\mathrm{w}, \mathrm{p} 2}=-u_{\mathrm{idm}, \mathrm{p}} / 2+u_{\mathrm{cm}, \mathrm{hf}}, \\
& u_{\mathrm{w}, \mathrm{n} 1}=-u_{\mathrm{idm}, \mathrm{n}} / 2-u_{\mathrm{cm}, \mathrm{hf}}, \\
& u_{\mathrm{w}, \mathrm{n} 1}=u_{\mathrm{idm}, \mathrm{n}} / 2-u_{\mathrm{cm}, \mathrm{hf}} .
\end{aligned}
$$

It can be seen that the ICMCI's winding voltages are defined only by the switching frequency $\mathrm{cm}$ voltage and the inner $\mathrm{dm}$ voltages, while the outer dm voltage is applied only to the differential mode inductor $L_{\mathrm{dm}}$ and the dc output $u_{\mathrm{pn}}$.

Simulation results of the ICMCI's winding voltages and the outer dm voltage for nominal operation are shown in Fig. 5(b). Compared to a non-interleaved SWISS Rectifier, as shown in Fig. 5(a), the (outer) dm voltage applied to $L_{\mathrm{dm}}$ is reduced which leads to a significant reduction of the peakto-peak ripple in $i_{\mathrm{odm}}$ compared to $i_{\mathrm{dm}}$. The same holds for the cm current $i_{\mathrm{cm}}$.

A drawing of the resulting switching frequency voltage and current waveforms is shown in Fig. 6 for $0^{\circ} \leq \omega t \leq 30^{\circ}$. It can be seen that the ICMCI's winding voltages $u_{\mathrm{w}, \mathrm{p} 1}$, $u_{\mathrm{w}, \mathrm{p} 2}, u_{\mathrm{w}, \mathrm{n} 1}$ and $u_{\mathrm{w}, \mathrm{n} 2}$ are periodic with the switching frequency, while the voltage $u_{\mathrm{odm}}$,hf applied to $L_{\mathrm{dm}}$ shows twice that frequency due to harmonic cancellation.

\section{ReCTIFIER PROTOTYPE}

For power supply systems which are operated 24/7, as in data centers, a high efficiency is desirable to minimize the
TABLE II

COMPONENTS USED IN THE HARdWARE PROTOTYPE

\begin{tabular}{ccc} 
& ICMCI & $\boldsymbol{L}_{\mathrm{dm}}$ \\
\hline Core & $4 \times \mathrm{U} 46 / 40 / 28-3 \mathrm{C} 94$ & $\mathrm{~F} 3 \mathrm{CC} 25$ \\
Wire & $0.4 \times 15 \mathrm{~mm}$ & $2.4 \times 6 \mathrm{~mm}$ \\
Turns & $4 \times 20$ & $2 \times 15$ \\
Volume & $420 \mathrm{~cm}^{3}$ & $249 \mathrm{~cm}^{3}$ \\
Losses & $5.6 \mathrm{~W}$ & $2.9 \mathrm{~W}$ \\
\hline & & \\
\hline $\mathrm{D}_{\mathrm{x} \overline{\mathrm{k}}}, \mathrm{D}_{\overline{\mathrm{kz}}}$ & $\mathrm{C} 2 \mathrm{M} 0025120$ & $P_{\text {loss }}=1.8 \mathrm{~W}$ \\
$\mathrm{~S}_{\overline{\mathrm{k}} \overline{\mathrm{k}}}$ & $\mathrm{C} 2 \mathrm{M} 0080120$ & $P_{\text {loss }}=0.8 \mathrm{~W}$ \\
$\mathrm{~S}_{\mathrm{x} \overline{\mathrm{p}} 1,2}, \mathrm{~S}_{\overline{\mathrm{n}} \mathrm{z} 1,2}$ & $\mathrm{C} 2 \mathrm{M} 0025120$ & $P_{\text {loss }}=4.9 \mathrm{~W}$ \\
$\mathrm{D}_{\mathrm{y} \overline{\mathrm{p}} 1,2}, \mathrm{D}_{\overline{\mathrm{n}} \mathrm{y} 1,2}$ & $\mathrm{C} 2 \mathrm{M} 0025120^{1}$ & $P_{\text {loss }}=1.0 \mathrm{~W}$ \\
\hline
\end{tabular}

cost of conversion losses and cooling and hence the operating costs of the system [17]. Furthermore a high efficiency over a wide range of output currents is desirable in applications where redundant supplies are used resulting in a nominal operation at half of the rated power or less. Therefore, a system which achieves an efficiency of $>99 \%$ for $P>$ $P_{\text {rated }} / 3$ for the operating condition listed in Table I was designed.

Silicon carbide (SiC) MOSFETs are selected due to their low conduction and switching losses and high blocking voltage rating $(1.2 \mathrm{kV})$ compared to $\mathrm{Si}$ IGBTs and Si MOSFETs $[18,19]$. Nanocrystalline core material (FINEMET) is used for $\mathrm{dm}$ inductor $L_{\mathrm{dm}}$ due to its high saturation flux density $(\approx 1.2 \mathrm{~T})$ and lower losses compared to amorphous alloys. For the current compensated ICMCI core 3 C 94 ferrite material is used due to its lower core losses. A symmetrical, cube-type core as shown in Fig. 7 is used for the ICMCI. This shape is achieved by using four conventional $\mathrm{C}$ cores, 


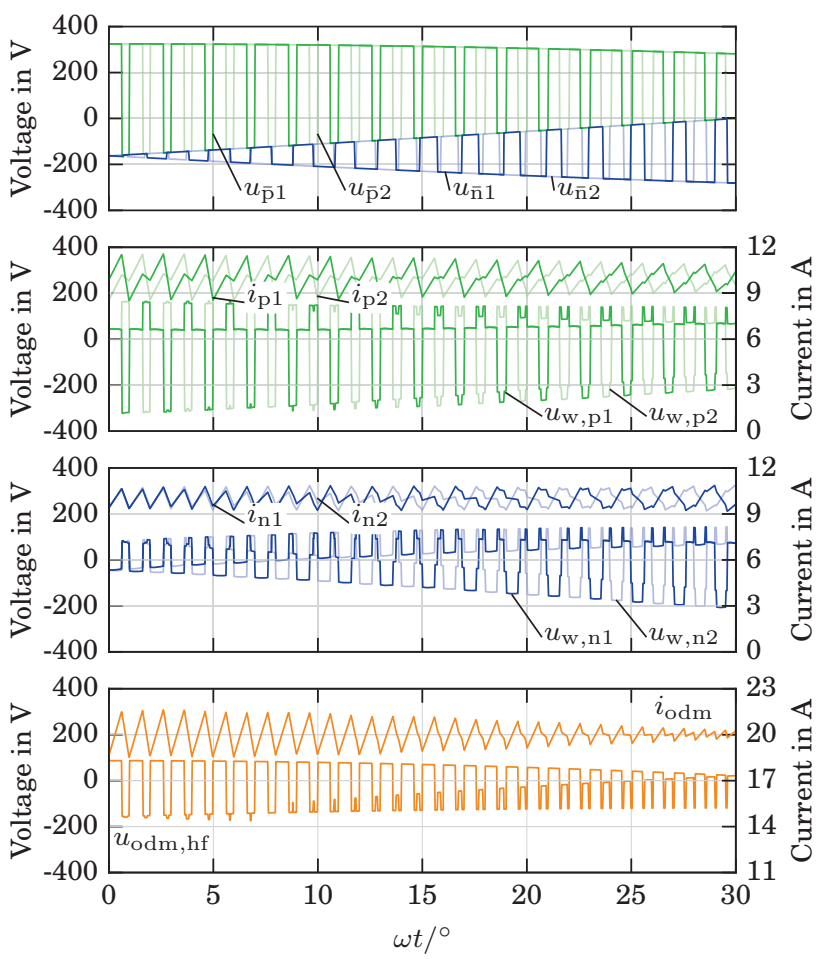

Fig. 6. Visualization of the resulting dc-dc converter output voltages $u_{\overline{\mathrm{p}} 1}$, $u_{\overline{\mathrm{p}} 2}$ and $u_{\overline{\mathrm{n}} 1}, u_{\overline{\mathrm{n}} 2}$ during a $30^{\circ}$ mains voltage sector, with a reduced switching frequency of $9 \mathrm{kHz}$. This results in the ICMCI voltages $u_{\mathrm{w}, \mathrm{p} 1}$, $u_{\mathrm{w}, \mathrm{p} 2}, u_{\mathrm{w}, \mathrm{n} 1}$ and $u_{\mathrm{w}, \mathrm{n} 2}$ and the outer dm voltage $u_{\mathrm{odm}, \mathrm{hf}}$ applied to $L_{\mathrm{dm}}$.
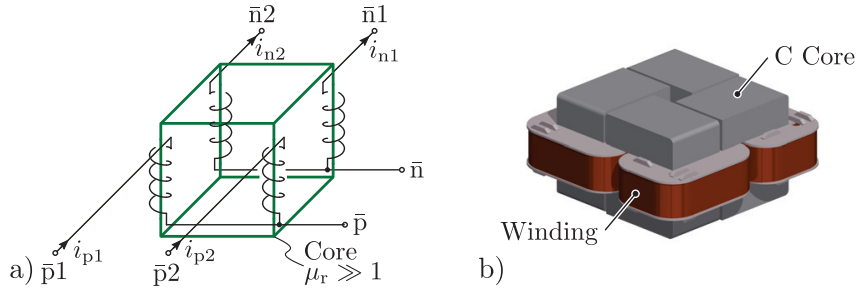

Fig. 7. (a) Structure of the implemented symmetrical, cube-type ICMCI core which is constructed from four $\mathrm{C}$ cores with one winding each as shown in (b).

each carrying one winding as shown in Fig. 7(b). The semiconductors and magnetic components selected for the prototype are listed in Table II.

The calculated losses of the selected components for nominal operation are shown in Fig. 8(a) with the corresponding volumes given in (b). About $60 \%$ of the total losses result from semiconductors, $13 \%$ from the main magnetic components and $27 \%$ from the EMI filter, control, gate drivers, auxiliary supply etc. A picture of the implemented hardware prototype, achieving a power density of $4.0 \mathrm{~kW} \mathrm{dm}^{-3}$ $\left(66 \mathrm{~W} \mathrm{in}^{-3}\right)$ is shown in Fig. 9.

Measurement results of the rectifier's mains voltages and currents at nominal operation are shown in Fig. 10. The resulting input currents $i_{\mathrm{a}, \mathrm{b}, \mathrm{c}}$ are nearly sinusoidal and free of distortions at the sector boundaries as expected from the presented simulation results. Note that the rectifier's control circuit is configured for ohmic mains behavior as described in [20]. An input current THD of $2.45 \%$ results for a mains voltage THD of $2.29 \%$. (a)

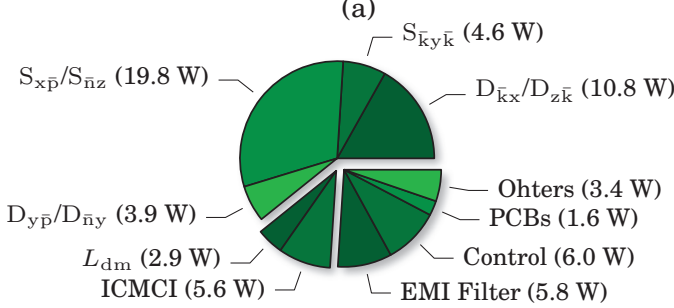

(b)

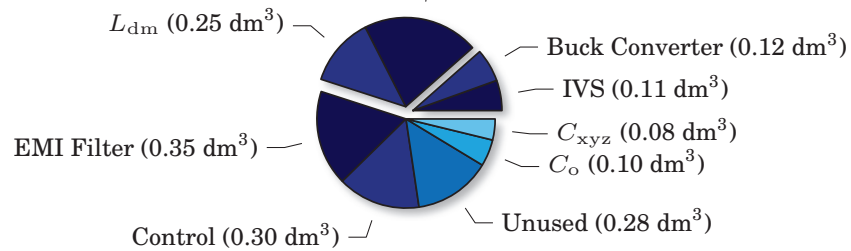

Fig. 8. Calculated losses of the rectifier's main components (cf. (a)) for nominal operation $\left(U_{\mathrm{pn}}=400 \mathrm{~V}, I_{1}=20 \mathrm{~A}\right)$. The control losses include DSP/FPGA, gate drivers, fans and auxiliary supply. The corresponding volumes in $\mathrm{dm}^{3}$ are shown in (b) $\left(1 \mathrm{dm}^{3}=61 \mathrm{in}^{3}\right)$.

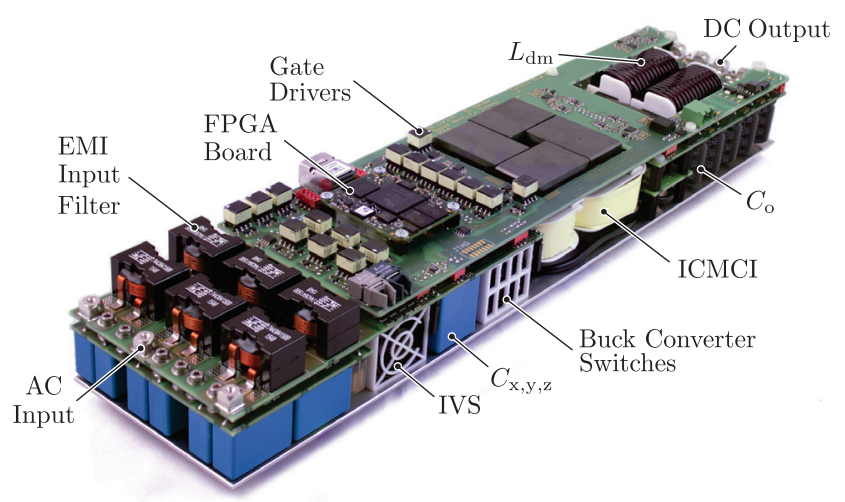

Fig. 9. Implemented $8 \mathrm{~kW} 400 \mathrm{~V}$ ac / $400 \mathrm{~V}$ dc interleaved SWISS Rectifier prototype ( $420 \mathrm{~mm} \times 95 \mathrm{~mm}$ x $50 \mathrm{~mm}$ ) with $>99 \%$ efficiency (cf. Fig. 11) and a power density of $4 \mathrm{~kW} \mathrm{dm}^{-3}\left(66 \mathrm{~W} \mathrm{in}^{-3}\right)$.

The calculated efficiency of the rectifier for $U_{\mathrm{pn}}=400 \mathrm{~V}$ as function of dc load current $I_{1}$ is shown in Fig. 11, together with measurement results taken using a Yokogawa WT3000 power analyzer. It can be seen that the measurement results of the prototype converter match the calculated efficiency

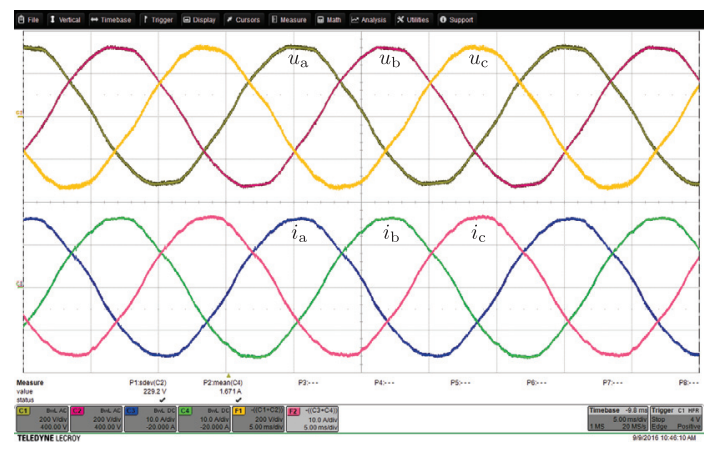

Fig. 10. Measured ac mains voltages $u_{\mathrm{a}, \mathrm{b}, \mathrm{c}}(200 \mathrm{~V} /$ div.) and converter input currents $i_{\mathrm{a}, \mathrm{b}, \mathrm{c}}(10 \mathrm{~A} / \mathrm{div}$.) for nominal operation. Note that the quantities for phases a and $\mathrm{b}$ were measured directly while those of phase $\mathrm{c}$ are created numerically as $u_{\mathrm{c}}=-u_{\mathrm{a}}-u_{\mathrm{b}}$ and $i_{\mathrm{c}}=-i_{\mathrm{a}}-i_{\mathrm{b}}$. 


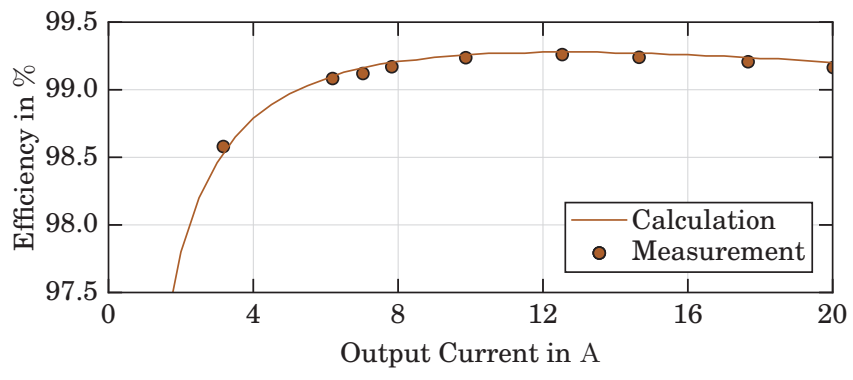

Fig. 11. Calculated and measured efficiency of the rectifier as function a of $I_{1}$, indicating that the converter achieves an efficiency above $99 \%$ for $>30 \%$ load with peak efficiency of $99.26 \%$. Measurements were taken on the prototype shown in Fig. 9 using a Yokogawa WT3000 power analyzer.

over a wide range of output currents. A peak efficiency of $\eta=99.26 \%$ (error range: $98.80 \%-99.74 \%$ ) was measured for $I_{1}=12.5 \mathrm{~A}$ and $\eta=99.16 \%$ (error range: $98.84 \%$ $99.49 \%)$ at rated load $I_{1}=20 \mathrm{~A}$.

\section{CONCLUSiON}

This paper describes a three-phase buck-type unity power factor SWISS Rectifier with interleaved dc-dc converter output stages. The system allows a single-stage conversion from the three-phase mains to a lower dc voltage. Using interleaved dc-dc converter stages reduces the input current and voltage ripples which improves the ac input current THD and reduces the dc output current ripple. Furthermore, the required dc output inductors can be combined into a current compensated Integrated Common Mode Coupled Inductor (ICMCI) and a differential mode inductor. Based on this approach a high efficiency interleaved SWISS Rectifier for dc distribution and power supply systems is designed, achieving a power density of $4 \mathrm{~kW} \mathrm{dm}^{-3}$. Measurements taken on a prototype verify an efficiency of $99.16 \%( \pm 0.32 \%)$ at nominal operation with $8 \mathrm{~kW}$ dc output power and a peak efficiency of $99.26 \%( \pm 0.48 \%)$. Note that for a similar $5 \mathrm{~kW}$ three-phase buck-type rectifier, based on Si MOSFETS and SiC diodes, an efficiency of $98.8 \%$ and a power density of $2.2 \mathrm{~kW} \mathrm{dm}^{-3}$ were reported in [11]. However, further research is required to assess potential benefits regarding efficiency and/or power density which could result from novel wide band-gap semiconductor devices such as monolithic bidirectional switches which could be used in the IVS [21].

\section{ACKNOWLEDGMENT}

The authors would like to thank ABB Switzerland Ltd. for the funding and for their support of this research project.

\section{REFERENCES}

[1] A. Pratt, P. Kumar and T. V. Aldridge, "Evaluation of 400V DC Distribution in Telco and Data Centers to Improve Energy Efficiency,' in Proc. of IEEE Telecommunications Energy Conference (INTELEC), Sept 2007, pp. 32-39.

[2] G. AlLee and W. Tschudi, "Edison Redux: 380 Vdc Brings Reliability and Efficiency to Sustainable Data Centers," IEEE Power and Energy Magazine, vol. 10, no. 6, pp. 50-59, Nov 2012.

[3] D. E. Geary, D. P. Mohr, D. Owen, M. Salato, and B. J. Sonnenberg, "380V DC Eco-System Development: Present Status and Future Challenges," in Proc. of 35th International Telecommunications Energy Conference (INTELEC), Oct 2013, pp. 1-6.
[4] T. Dragičević, X. Lu, J. C. Vasquez and J. M. Guerrero, "DC Microgrids - Part II: A Review of Power Architectures, Applications and Standardization Issues," IEEE Transactions on Power Electronics, vol. 31, no. 5, pp. 3528-3549, May 2016.

[5] D. Marquet, T. Tanaka, K. Murai, T. Toru and T. Babasaki, "DC Power Wide Spread in Telecom/Datacenter and in Home/Office with Renewable Energy and Energy Autonomy," in Proc. of 35th International Telecommunications Energy Conference (INTELEC), Oct 2013, pp. $1-6$.

[6] T. Soeiro, T. Friedli and J. W. Kolar, "Three-Phase High Power Factor Mains Interface Concepts for Electric Vehicle Battery Charging Systems," in Proc. of Applied Power Electronics Conference and Exposition (APEC), Feb 2012, pp. 2603-2610.

[7] D. Aggeler, F. Canales, H. Zelaya-De La Parra, A. Coccia, N. Butcher and O. Apeldoorn, "Ultra-Fast DC-Charge Infrastructures for EVMobility and Future Smart Grids," in Proc. of Innovative Smart Grid Technologies Conference Europe (ISGT), Oct 2010, pp. 1-8.

[8] A. Kuperman, U. Levy, J. Goren, A. Zafransky and A. Savernin, "Battery Charger for Electric Vehicle Traction Battery Switch Station," IEEE Transactions on Industrial Electronics, vol. 60, no. 12, pp. 53915399, Dec 2013.

[9] ETSI, "Environmental Engineering (EE); Power Supply Interface at the Input to Telecommunications and Datacom (ICT) Equipment; Part 3: Operated by Rectified Current Source, Alternating Current Source or Direct Current Source up to $400 \mathrm{~V}$; Sub-part 1: Direct Current Source up to 400V," EN 300 132-3-1, Feb 2012.

[10] J. W. Kolar and T. Friedli, "The Essence of Three-Phase PFC Rectifier Systems - Part I," IEEE Transactions on Power Electronics, vol. 28 , no. 1, pp. 176-198, Jan 2013.

[11] A. Stupar, T. Friedli, J. Miniböck, J. W. Kolar , "Towards a 99\% Efficient Three-Phase Buck-Type PFC Rectifier for 400-V DC Distribution Systems," IEEE Transactions on Power Electronics, vol. 27, no. 4, pp. 1732-1744, April 2012.

[12] L. Schrittwieser, J. W. Kolar and T. B. Soeiro, "Novel SWISS Rectifier Modulation Scheme Preventing Input Current Distortions at Sector Boundaries," IEEE Transactions on Power Electronics, vol. PP, no. 99, pp. 1-1, 2016.

[13] N. V. Olarescu, M. C. Ancuti, C. Sorandaru,S. Musuroi, M. Svoboda, A. Hedes, D. Popovici and M. Wienmann, "Performances/Efficiency Analysis for High Efficiency Three-Phase Buck-Type PFC Rectifiers,' in Proc. of European Conference on Power Electronics and Applications (EPE ECCE-Europe), Sept 2015, pp. 1-9.

[14] M. Hirakawa, Y. Watanabe, M. Nagano, K. Andoh, S. Nakatomi, S. Hashino and T. Shimizu, "High Power DC/DC Converter using Extreme Close-Coupled Inductors aimed for Electric Vehicles," in Proc. of International Power Electronics Conference (IPEC), June 2010, pp. 2941-2948.

[15] F. Forest, E. Labouré, T. A. Meynard and V. Smet, "Design and Comparison of Inductors and Intercell Transformers for Filtering of PWM Inverter Output," IEEE Transactions on Power Electronics, vol. 24, no. 3, pp. 812-821, March 2009.

[16] B. Cougo, T. Friedli, D. O. Boillat and J. W. Kolar, "Comparative Evaluation of Individual and Coupled Inductor Arrangements for Input Filters of PV Inverter Systems," in Proc. of International Conference on Integrated Power Electronics Systems (CIPS), March 2012, pp. 1-8.

[17] M. E. Jacobs, "Worth of a Watt: The New Economics and Technologies," in Proc. of Telecommunications Energy Conference (INTELEC), Sept 2008, pp. 1-7.

[18] Q. Wang, X. Zhang, R. Burgos, D. Boroyevich, A. White and M. Kheraluwala, "Design and Implementation of Interleaved Vienna Rectifier with Greater than 99\% Efficiency," in Proc. of Applied Power Electronics Conference and Exposition (APEC), March 2015, pp. 7278.

[19] R. M. Burkart and J. W. Kolar, "Comparative Evaluation of SiC and Si PV Inverter Systems Based on Power Density and Efficiency as Indicators of Initial Cost and Operating Revenue," in Proc. of Control and Modeling for Power Electronics Workshop (COMPEL), June 2013, pp. $1-6$.

[20] L. Schrittwieser, M. F. Vancu, J. W. Kolar and T. B. Soeiro, "Control of the Input Characteristic and the Displacement Factor of Uni- and Bidirectional SWISS Rectifier for Symmetrical and Unsymmetrical Three-Phase Mains," in Proc. of International Conference on Power Electronics (ICPE-ECCE Asia), June 2015, pp. 40-47.

[21] T. Morita, M. Yanagihara, H. Ishida, M. Hikita, K. Kaibara, H. Matsuo, Y. Uemoto, T. Ueda, T. Tanaka and D. Ueda, " $650 \mathrm{~V} 3.1 \mathrm{~m} \Omega \mathrm{cm}^{2} \mathrm{GaN}-$ Based Monolithic Bidirectional Switch Using Normally-Off Gate Injection Transistor," in Proc of. International Electron Devices Meeting, Dec 2007, pp. 865-868. 